GPJI 4(1)(2020)

\title{
EFEKTIVITAS PEMBELAJARAN SPORT MASSASE BERBASIS MULTIMEDIA INTERAKTIF UNTUK MAHASISWA PENDIDIKAN JASMANI, KESEHATAN DAN REKREASI
}

\begin{abstract}
Tatok Sugiarto $^{1}$, Ari Wibowo Kurniawan ${ }^{2}$, Sugiyanto ${ }^{3}$
Universitas Negeri Malang tatok.sugiarto.fik@um.ac.id

\begin{tabular}{l}
\hline Info Artikel \\
Sejarah Artikel: \\
Diterima: April-2020 \\
Disetujui: Mei-2020 \\
Dipublikasikan: Juni-2020 \\
Kata Kunci: \\
multimedia interaktif, sport \\
massase, mahasiswa pendidikan \\
jasmani
\end{tabular}

\section{Abstrak}

Perkembangan teknologi mengharuskan para pendidik untuk lebih kreatif dalam memanfaatkan media pembelajaran, sehingga dengan multimedia interaktif dapat memfasilitasi pembelajaran sport massase agar lebih efektif dan efisien. Tingkat keefektifan dan efisiensi pembelajaran dengan multimedia interaktif perlu dikaji sehingga akan menemukan formula yang benar dan tepat dalam proses pembelajaran sport massase. Tujuan penelitian adalah untuk memperoleh data empiris tentang efektivitas dan efisiensi hasil pembelajaran sport massase dengan multimedia interaktif pada mahasiswa pendidikan jasmani, kesehatan dan rekreasi. Metode penelitian ini penelitian eksperimen dengan menggunakan Pre-Test - Post-Test Control Group Design. Nilai gain score keterampilan sport masase kelompok kontrol memperoleh/rata-rata 0,37 yang artinya adalah perbandingan antara nilai Pre-Test dan Post-Test mengalami perbedaan dalam kategori sedang. Nilai gain score keterampilan sport masase kelompok uji coba adalah 0,82 yang artinya adalah perbandingan antara nilai Pre-Test dan PostTest mengalami perbedaan dalam kategori tinggi. Dapat disimpulkan bahwa pembelajaran multimedia interaktif lebih efektif karena dapat memfasilitasi dan mengatasi kesulitan-kesulitan mahasiswa dalam pembelajaran sport massase.
\end{abstract}

Abstract

Technology development that requires educators to be more creative in using learning media, so that interactive multimedia can facilitate sports learning to be more effective and efficient. The level of effectiveness and efficiency of learning with interactive multimedia needs to be studied so that it will find the correct and correct formula in the sports massage learning process. The research objective is to obtain empirical data about the benefits and efficiency of massase learning outcomes with interactive multimedia on physical education, health and recreation students. This research method is an experimental study using Pre-Test - Post-Test Control Group Design. The gain value of the sports skills score of the control group obtained an average of 0.37 which means that compared to the value of the Pre-Test and Post-Test increasingly varied in the medium category. The score for obtaining a group trial skills score is 0.82 which means that the scores between the Pre-Test and Post-Test are increasingly different in the high category. Can deny that interactive multimedia learning is more effective because it can facilitate and overcome the difficulties of students in learning sports using massase.

(C) 2020 Universitas Negeri Malang

Alamat korespondensi: ISSN: 2614-8293 (Online)

E-mail: tatok.sugiarto.fik@um.ac.id 


\section{PENDAHULUAN}

Undang-Undang Republik Indonesia Nomor 3 tahun 2005 tentang sistem keolahragaan nasional (UU-SKN), pasal 1 ayat 1 di jelaskan bahwa "keolahragaan adalah segala aspek yang berkaitan dengan olahraga yang mememerlukan pengaturan, pendidikan, pembelajaran, pembinaan, pengembangan, dan pengawasan" (Kemenegpora, 2007:3) . dari pasal ini dapat diaplikasikan ke dalam dunia pendidikan, bahwa untuk menguasai dan memperdalam ilmu keolahragaan perlu pembelajaran. dan pembelajaran tersebut harus didesain dengan proses dan variasi yang efektif dan efisien, sehingga peserta didik akan lebih maksimal dalam memperoleh pengetahuan tentang keolahragaan yang dipelajarinya. pada saat ini pembelajaran mengenai keolahragaan dapat diperoleh melalui pendidikan formal. dalam aktivitas olahraga terdapat pencegahan-pencegahan yang dapat dilakukan untuk menghindari cedera. Selain melakukan pemanasan dapat juga dibantu dengan treatment sport massase.

Massase merupakan salah satu di antara cara-cara perawatan tubuh yang paling tua dan paling bermanfaat dalam perawatan fisik (badan). dalam ilmu tata rias, massase dapat digunakan untuk kesehatan dan kecantikan. untuk menguasai teknik-teknik massase perlu memiliki pengetahuan mengenai antomi (ilmu urai tubuh) dan latihan melakukan gerakan massase yang cukup banyak (Supriyadi \& Wardani, 2009). Massase mengarahkan penerapan manipulasi (penanganan) perawatan dari bagian luar kepada tubuh. Massase selalu harus ditunjukkan pada kulit dengan menggunakan cream massase. penggunaan cream mempermudah gerakan tangan yang lebih sempurna, dan mencegah lecet/rusaknya jaringan-jaringan sebelum melakukan massase, kulit muka dan leher harus dibersihkan dahulu dengan cleancing.

Sulistyorini (2012:11) menjelaskan macam-macam massase yang dapat diberikan pada seseorang antara lain: (a) massase therapeutis (pengobatan) yang bertujuan untuk penyembuhan, dalam arti dengan memberikan massase orang ingin mendapatkan pengaruh yang sebaik-baiknya terhadap keadaan pathologis maupun postraumatis, (b) beauty massase atau cosmetik massase diberikan di salon-salon kecantikan dengan tujuan untuk memperbaiki peredaran darah, merawat dan mencegah timbulnya keriput atau lipatan pada kulit terutama pada wajah, (c) hygiene massase diberikan pada pegawai atau pekerja yang dalam melakukan pekerjaannya banyak duduk, berdiri atau terlalu sibuk, (d) sport massase diketahui kegunaan terhadap manusia, menyegarkan atau menghilangkan kelelahan, untuk menaikkan kondisi fisik seseorang (warming up), untuk membantu prestasi olahragawan, untuk membantu mempercepat penyembuhan cedera tertentu.

Mahasiswa Pendidikan Jasmani dan Kesehatan FIK-UM dalam mempersiapkan diri untuk terjun kemasyarakat perlu dibekali berbagai keterampilan disamping penguasaan teori juga keterampilan dalam mempraktekan semua yang tersusun dalam kurikulum. Salah satu mata kuliah praktek yang harus dikuasai adalah massase. Pada matakuliah massase mempunyai kontribusi penting dalam mempertahankan dan meningkatkan kondisi tubuh seseorang. Pada matakuliah massase seorang mahasiswa harus memiliki rasa percaya diri dalam mempraktekkannya. penguasaan teknikteknik yang benar harus dilakukan dengan sebaik mungkin agar dapat memperoleh hasil maksimal. untuk itu perlunya kemampuan seorang dosen untuk mendesain program pembelajaran yang bervariasi, menarik dan aman untuk dilakukan oleh mahasiswa.

Pembelajaran materi massase pada saat ini masih belum maksimal, ini salah satunya diakibatkan karena model pembelajaran yang diberikan ke mahasiswa masih konvensional dan kurang dalam menerapkan pembelajaran dengan memanfaatkan IPTEK, oleh sebab itu penggunaan IPTEK dalam peningkatan kemampuan mahasiswa saat ini harus dilakukan. untuk itu, pola pikir kita harus dirubah agar maju dengan menggunakan bantuan teknologi, sehingga kemampuan mahasiswa dalam menguasai materi massase dapat lebih meningkat. hal ini diperkuat dengan pernyataan Duffy (1993:22) bahwa pemanfaatan berbagai macam sumber belajar merupakan upaya dalam pemecahan masalah belajar. kesadaran tentang kebutuhan teknologi harus dimiliki oleh calon guru pendidikan jasmani (Varol, 2014:157).

Efektivitas pembelajaran dapat dilihat dari aktivitas siswa selama pembe-lajaran berlangsung, respon siswa terhadap pembelajaran dan penguasaan konsep siswa. Untuk mencapai suatu konsep pembelajaran yang efektif dan efisien perlu adanya hubungan timbal balik antara siswa dan guru untuk mencapai suatu tujuan secara bersama, selain itu juga harus disesuaikan dengan kondisi lingkungan sekolah, sarana dan prasarana, serta media pembelajaran yang dibutuhkan untuk membantu tercapainya seluruh aspek perkembangan siswa. Kegiatan pembelajaran yang efektif sangat dibutuhkan anak untuk membantu mengembangkan daya pikir anak dengan tanpa mengesampingkan tingkat pemahaman anak sesuai dengan usia perkembangannya. Efektivitas 
pembelajaran merupakan suatu ukuran keberhasilan dari proses interaksi dalam situasi edukatif untuk mencapai tujuan pembelajaran. Dilihat dari aktivitas selama pembelajaran, respon dan penguasaan konsep .

Berdasarkan hasil analisis kebutuhan dengan observasi pada matakuliah massase dapat disimpulkan bahwa: (1) belum pernah digunakannya media pembelajaran dalam perkuliahan massase, sehingga perlu adanya pengembangan sport massase dikemas dalam multimedia interaktif dengan memanfaatkan laptop yang hampir dimiliki oleh setiap mahasiswa. (2) mahasiswa merasa belum menguasai benar teknik-teknik sport massase secara maksimal karena hanya dilakukan secara konvensional dan gaya belajar tiap mahasiswa berbeda. (3) perlunya menguji keefektifan pembelajaran sport masase dengan menggunakan multimedia interaktif.

Berdasarkan teori yang dipaparkan pada latar belakang dan diperkuat dengan temuan-temuan di lapangan yang didapat dari hasil analisis kebutuhan maka diperlukan inovasi pembelajaran pada massase menggunakan multimedia interaktif. Hasil pembelajaran yang sedang dikembangkan ini dapat membantu mahasiswa untuk menguasai keterampilan teknik-teknik sport massase dan dikemas semenarik mungkin agar dapat memudahkan mahasiswa. Untuk itu peneliti akan menguji dan mengkaji keefektifan multimedia Interaktif pembelajaran Sport Massase untuk Mahasiswa Pendidikan Jasmani dan Kesehatan FIK-UM.

\section{METODE}

Penelitian ini dilaksanakan pada Jurusan Pendidikan Jasmani, Kesehatan dan Rekreasi, Fakultas Ilmu Keolahragaan Universitas Negeri Malang. Dengan jumlah total sampel 80 mahasiswa angkatan 2017. Sampel yang digunakan 40 orang mahasiswa kelompok Uji coba (pembelajaran sport masase berbasis multimedia interaktif) dan 40 orang kelompok kontrol (pembelajaran sport masase berbasis konvensional). Penelitian ini menitikberatkan sejauh mana efektivitas penggunaan multimedia interaktif dalam proses pembelajaran sport masase dalam meningkatkan hasil belajar mahasiswa. Dilihat dari tujuannya, penelitian ini termasuk penelitian eksperimental atau uji efektivitas yaitu penelitian yang dilakukan dengan memberikan perlakuan (treatment) tertentu terhadap subjek penelitian yang bersangkutan dengan menggunakan desain eksperimen Pre-Test - Post-Test Control Group Design (Sugiyono, 2015). Uji efektivitas ini mempunyai tujuan untuk mengetahui apakah desain pembelajaran dapat diterapkan dengan baik dan benar, serta dapat dikuasai oleh subjek.

Tabel 1. Desain Penelitian dalam Uji Efektivitas Model

\begin{tabular}{llll}
\hline Subjek & Pre-Test & Perlakuan & Post-Test \\
\hline R1 & O1 & P & O2 \\
\hline R2 & O3 & P & O4 \\
\hline
\end{tabular}

Langkah yang dilakukan dalam uji coba ini antara lain: (1) Menetapkan subjek penelitian; (2) Melaksanakan pre-test (O1) untuk kelompok eksperimen (R1); (3) Melaksanakan pre-test (O3) untuk kelompok kontrol (R2); (4) Memberi perlakuan untuk kelompok eksperimen (R1) dan kelompok kontrol (R2); (5) Melaksanakan post-test (O2) untuk kelompok eksperimen (R1); (6) Melaksanakan posttest (O4) untuk kelompok kontrol (R2); (7) Mencari skor rata-rata pre-test dan post-test dan dibandingkan antara keduanya; (8) mencari selisih perbedaan kedua rata-rata tersebut melalui metode Gain score, untuk mengetahui tingkat kebermaknaan selisih nilai pre-test dengan post-test.

Gain score merupakan metode yang sesuai untuk menganalisis hasil Pre-Test dan Post-Test pada kelas eksperimen dan kontrol, serta menunjukan tingkat keefektifaan pengajaran. Berikut merupakan rumus gain score (Hake, 1999): 


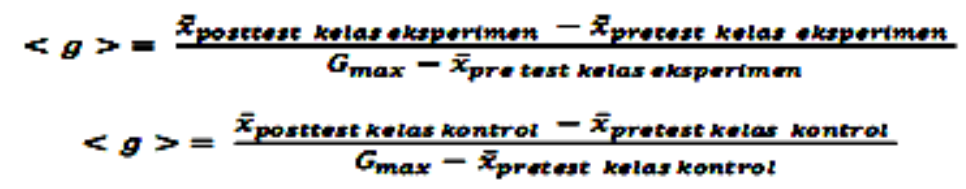

Keterangan :

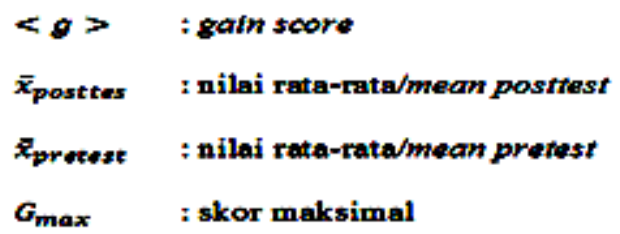

Tabel 2. Tabel kriteria indeks gain score

HASIL

\begin{tabular}{ll}
\hline Indeks Gain & Keterangan \\
\hline Indeks Gain $<0,30$ & Rendah \\
\hline $0,30 \leq$ Indeks Gain $\leq 0,70$ & Sedang \\
\hline Indeks Gain $>0,70$ & Tinggi \\
\hline
\end{tabular}

\section{Data Keterampilan Kelompok Kontrol}

Penilaian Pre-Test Keterampilan Sport masase Kelompok Kontrol

Untuk mengetahui keterampilan awal mahasiswa, peneliti melakukan pre-test kelompok mahasiswa. Hasil penilaian pre-test keterampilan sport masase pada kelompok kontrol pembelajaran sport masase memperoleh nilai rata-rata 57,73 yang artinya rata-rata cukup.

Penilaian Post-Test Keterampilan Sport masase Kelompok Kontrol

Sedangkan untuk mengetahui kemajuan hasil dari proses pembelajaran sport masase kelompok kontrol, peneliti melakukan Post-Test keterampilan sport masase mahasiswa kelompok kontrol yakni kelompok tanpa diberikan perlakuan khusus menggunakan multimedia Interaktif pembelajaran sport masase. Hasil penilaian Post-Test keterampilan sport masase pada kelompok kontrol pembelajaran sport masase memperoleh nilai 73,45 yang artinya rata-rata baik

Perbandingan Nilai Pre-Test dan Post-Test keterampilan Sport Masase Kelompok Kontrol

Dengan diperolehnya data Pre-Test dan Post-Test keterampilan sport masase kelompok kontrol, selanjutnya peneliti melakukan analisis perbedaan nilai Pre-Test dan posttes menggunakan Gain score. Dengan demikian maka akan diperoleh hasil besaran kontribusi proses dalam mempengaruhi nilai keterampilan pada Post-Test. Hasil skor gain yang diperoleh rata-rata 0,37 yang artinya adalah perbandingan antara nilai Pre-Test dan Post-Test mengalami perbedaan dalam kategori sedang. Proses pembelajaran pada kelompok kontrol memiliki kontribusi pada keterampilan mahasiswa pada tingkatan sedang. Berikut adalah diagram batang nilai Pre-Test dan Post-Test . 


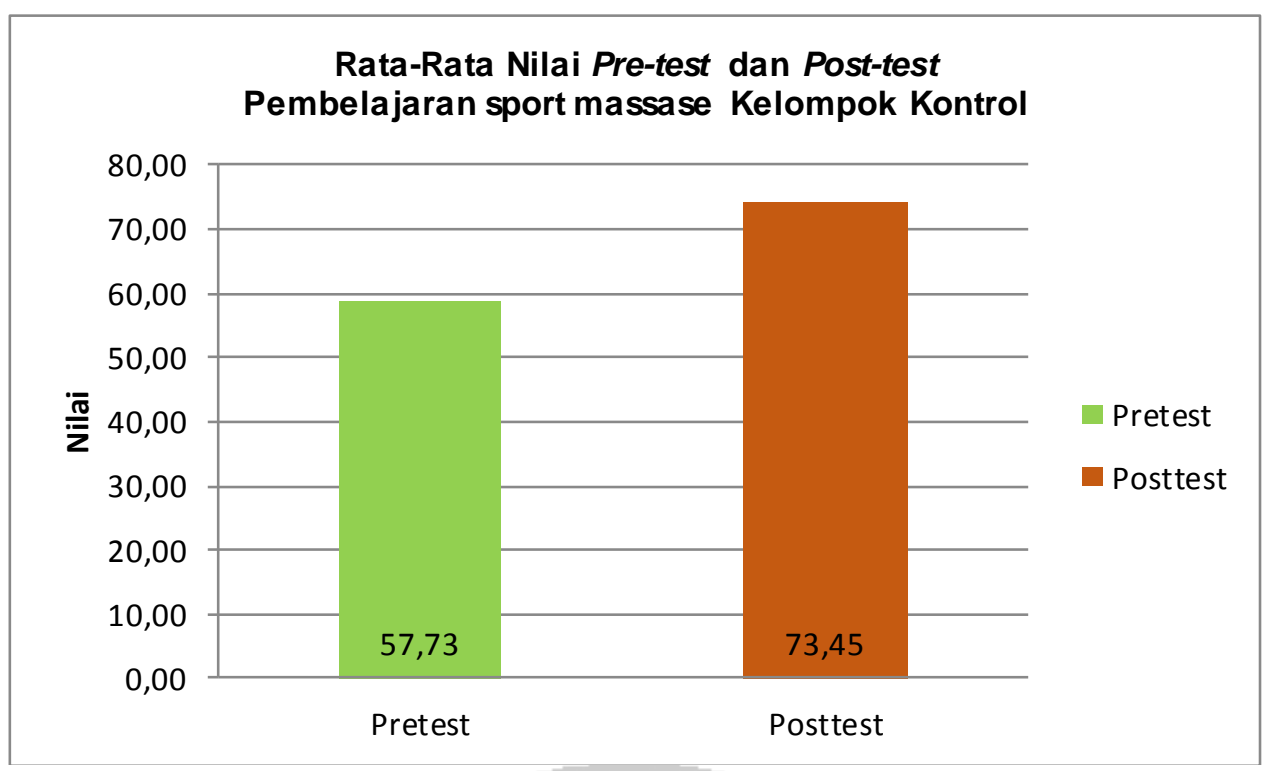

Dari hasil ini dapat disimpulkan bahwa proses pembelajaran belum maksimal, karena variasi pembelajaran dan media pembelajaran belum digunakan secara efektif. Dalam kaitannya dengan fungsi media pembelajaran, dapat ditekankan beberapa hal berikut ini: 1. Bahwa media sebagai sarana bantu untuk mewujudkan situasi pembelajaran yang lebih efektif. 2. Sebagai salah satu komponen yang saling berhubungan dengan komponen lainnya dalam rangka menciptakan situasi belajar yang diharapkan. 3. Mempercepat proses belajar. 4. Meningkatkan kualitas proses belajar-mengajar. 5. Mengkongkritkan yang abstrak sehingga dapat mengurangi terjadinya penyakit verbalisme. (Nurseto, 2011)

\section{Data Nilai Keterampilan Kelompok Uji Coba}

Penilaian Pre Test Keterampilan Sport masase Kelompok Uji Coba

Berdasarkan hasil analisis data bahwa rata-rata nilai Pre-Test keterampilan sport masase kelompok uji coba adalah 58,80 yang artinya keterampilan sport masase mahasiswa sebelum mendapatkan perlakuan adalah cukup baik.

Penilaian Post Test Keterampilan Sport masase Kelompok Uji Coba

Setelah melakukan Pre-Test, kemudian kelompok uji coba diberikan perlakuan pembelajaran sport masase berbasis multimedia interaktif. Berdasarkan analisis data yang diperoleh bahwa rata-rata nilai Post-Test keterampilan sport masase kelompok uji coba adalah 92,27 yang artinya keterampilan sport masase mahasiswa setelah mendapatkan perlakuan adalah sangat baik.

Perbandingan Nilai Pre-Test dan Post-Test Keterampilan Sport masase Kelompok Uji Coba

Untuk memperoleh data tingkat kontribusi perlakuan terhadap hasil belajar mahasiswa, maka peneliti melakukan analisis gain score dengan mencari kategori selisih nilai Pre-Test dan Post-Test mahasiswa kelompok uji coba. Berikut data analisis gain score keterampilan sport masase mahasiswa kelompok uji coba adalah 0,82 yang artinya adalah perbandingan antara nilai Pre-Test dan Post-Test mengalami perbedaan dalam kategori tinggi. Perlakuan pembelajaran sport masase berbasis multimedia interaktif pada kelompok uji coba memiliki kontribusi yang tinggi pada keterampilan mahasiswa. Berikut adalah diagram batang nilai Pre-Test dan Post-Test kelompok uji coba. 


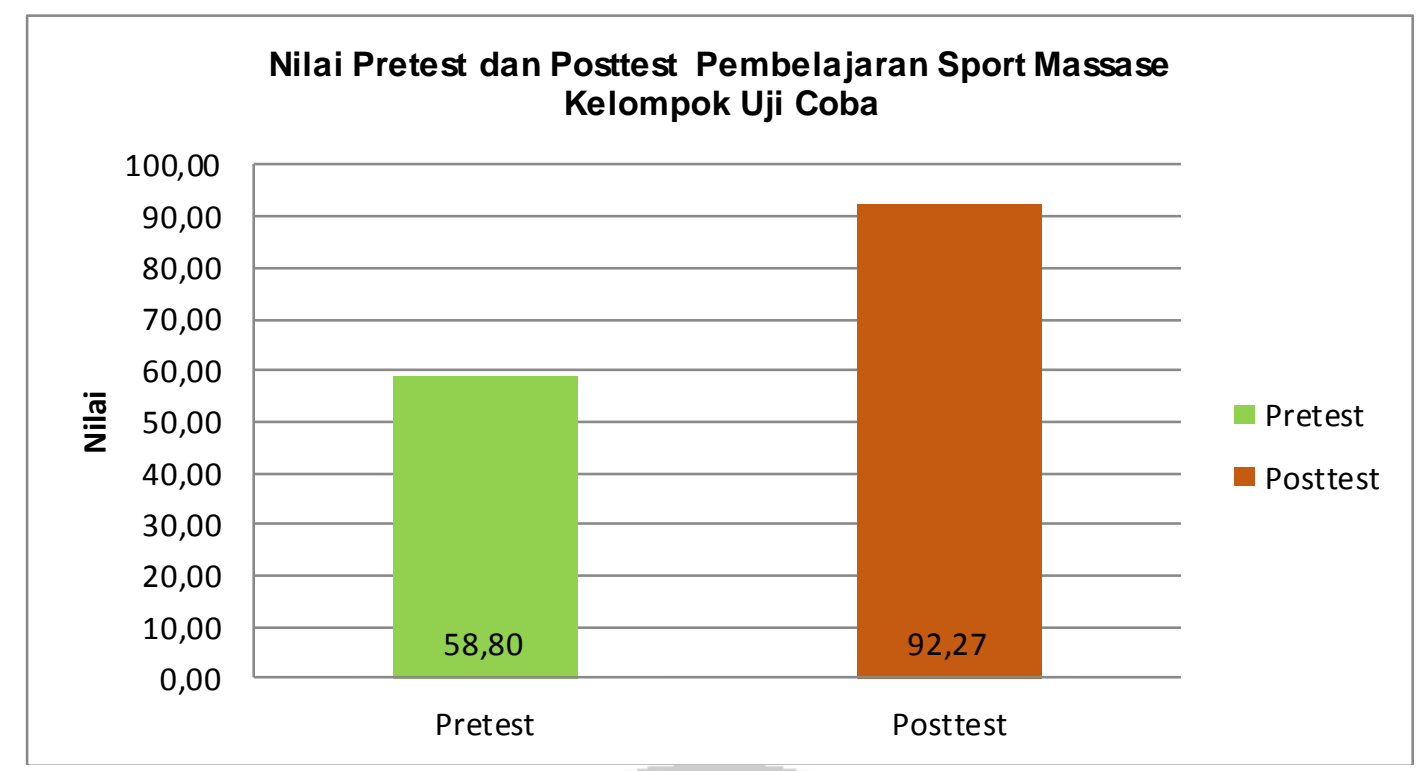

\section{PEMB AHASAN}

Pada matakuliah sport massase mempunyai kontribusi penting dalam aktivitas olahraga karena dapat menjadi pencegahan-pencegahan yang dapat dilakukan untuk menghindari cedera. Selain melakukan pemanasan dapat juga dibantu dengan treatment sport massase. Sport massase merupakan salah satu di antara cara-cara perawatan tubuh yang paling tua dan paling bermanfaat dalam perawatan fisik (badan). Dalam ilmu tata rias, sport massase dapat digunakan untuk kesehatan dan kecantikan. Untuk menguasai teknik-teknik sport massase perlu memiliki pengetahuan mengenai antomi (ilmu urai tubuh) dan latihan melakukan gerakan sport massase yang cukup banyak (Supriyadi \& Wardani, 2009). Sport massase mengarahkan penerapan manipulasi (penanganan) perawatan dari bagian luar kepada tubuh. Sport massase selalu harus ditunjukkan pada kulit dengan menggunakan cream sport massase. Penggunaan cream mempermudah gerakan tangan yang lebih sempurna, dan mencegah lecet/rusaknya jaringan-jaringan.

Berdasarkan produk yang dikembangakan dalam kenyataannya membutuhkan pengkajian ulang keberadaannya, karena setelah melalui proses penelitian terdapat beberapa hal yang perlu unt uk dilakukan perbaikan. Produk pengembangan sport massase untuk mahasiswa pendidikan jasmani dan kesehatan FIK-UM dalam bentuk multimedia interaktif yang dikemas menggunakan DVD memiliki kelebihan-kelebihan sebagai salah satu alternatif yang dapat dimanfaatkan dalam permasalahan yang terjadi pada proses perkuliahan dengan membuat pembelajaran yang memudahkan mahasiswa pada matakuliah massase dan dengan memanfaatkan kemajuan teknologi.

Pembelajaran materi sport massase pada saat ini masih belum maksimal, ini salah satunya diakibatkan karena model pembelajaran yang diberikan ke mahasiswa masih konvensional dan kurang dalam menerapkan pembelajaran XXI dengan memanfaatkan IPTEK. Oleh sebab itu penggunaan IPTEK dalam peningkatan kemampuan mahasiswa saat ini harus dilakukan. Untuk itu, pola pikir kita harus dirubah agar maju dengan menggunakan bantuan teknologi, sehingga kemampuan mahasiswa dalam menguasai materi sport massase dapat lebih meningkat. Hal ini diperkuat dengan pernyataan Duffy dkk (1992:22) bahwa pemanfaatan berbagaimacam sumber belajar merupakan upaya dalam pemecahan masalah belajar. Kesadaran tentang kebutuhan teknologi harus dimiliki oleh calon guru pendidikan jasmani (Varol, 2014:157).

Menurut Vernadakis (2011:439-443) bahwa penggunaan teknologi dalam pembelajaran menarik minat dan respek siswa terhadap proses pembelajaran jika dibandingkan dengan pembelajaran kovensional. Sedangkan Efrina (2013:65-78) menjelaskan bahwa pendidikan diperlukan pembaharuan dalam hal media pembelajaran agar menarik menjadi lebih efisien, efektif, dan relevan dengan perkembangan IPTEK. Salah satu teknologi yang dapat meningkatkan hasil belajar adalah multimedia interaktif selaras dengan penelitian dari (Wiendartum dkk (2007:7) bahwa pembelajaran berbasis multimedia berpengaruh terhadap peningkatan hasil belajar. 
Deliyannis (2012:5) berpendapat bahwa multimedia digunakan untuk mendefinisikan area yang sangat luas yang mencakup bidang informatika, telekomunikasi, sektor produksi audio visual, bioskop dan digital media. Darmawan (2012:53) menjelaskan bahwa multimedia interaktif dapat juga dipandang sebagai upaya pemanfaatan komputer untuk membuat dan menggabungkan teks, grafik, audio, gambar bergerak (video dan animasi) dengan menggabungkan link dan tool yang memungkinkan pemakai untuk melakukan navigasi, berinteraksi, berkreasi dan berkomunikasi baik dalam konteks face to face, offline konteks, maupun online konteks. pendapat lain disampaikan oleh Munir (2012:128) multimedia interaktif adalah suatu tampilan multimedia yang dirancang oleh desainer agar tampilannya memebuhi fungsi menginformasikan pesan dan memiliki interaktifitas kepada pengguna.

Dwiyogo (2008:92) menjelaskan bahwa multimedia interaktif merupakan sistem media penyampaian yang menyajikan materi video rekaman dengan pengendalian komputer kepada penonton yang tidak hanya mendengar dan melihat video dan suara, tetapi juga memberikan respon yang aktif dan respon itu yang menentukan kecepatan dan sekuensi penyajian. Daryanto (2015:53) multimedia interaktif adalah suatu multimedia yang dilengkapi alat pengontrol yang dapat dioperasikan pengguna sesuai dengan yang dikehendakinya. Multimedia interaktif adalah suatu multimedia yang dilengkapi dengan alat pengontrol yang dapat dioperasikan oleh pengguna, contoh multimedia interaktif adalah multimedia pembelajaran interaktif, aplikasi game, dan lain-lain (Ahmadi, Amri, dan Elisah 2011:158).

Cairncross \& Mannion (2001) menjelaskan kelebihan multimedia interaktif adalah memberikan pembelajaran sehingga membuat siswa tidak bosan dengan adanya unsir teks, gambar, dan video. sedangkan Munir (2012:113) menjelaskan keunggulan multimedia interaktif adalah: (1) sistem pembelajaran inovetif dan interaktif, (2) menggabungkan teks, gambar, dan video, (3) menambah motivasi peserta didik, (4) mampu menvisualisasikan materi yang selama ini sulit diterangkan. Sehingga dengan menggunakan metode multimedia interaktif dalam pembelajaran dapat meningkatkan hasil belajar peserta didik serta proses pembelajaran dapat berjalan dengan sempurna dan efektif. Kelebihan multimedia interaktif adalah menggabungkan berbagai macam media serta dapat digunakan untuk pembelajaran mandiri maupun klasikal sehingga peserta didik dengan berbagai tingkatan kemampuan dapat menggunakan tanpa merasa kesulitan karena dilengkapai dengan petunjuk penggunaan.

Hamalik (2001)menyatakan bahwa pembelajaran yang efektif adalah pembelajaran yang menyediakan kesempatan belajar sendiri atau melakukan aktivitas seluas-luasnya kepada siswa untuk belajar. Penyediaan kesempatan belajar sendiri dan beraktivitas seluas-luasnya diharapkan dapat membantu siswa dalam memahami konsep yang sedang di pelajari. Vigotsky (Mulyasa, 2012) juga berpendapat bahwa pengalaman interaksi sosial merupakan hal penting bagi perkembangan keterampilan berfikir (thinking skill). Efektivitas pembelajaran adalah ukuran keberhasilan dari suatu proses interaksi antar siswa maupun antara siswa dengan guru dalam situasi edukatif untuk mencapai tujuan pembelajaran.

Hasil penelitian Ampa (2015) menunjukkan bahwa dengan menggunakan materi pembelajaran dalam bentuk multimedia interaktif, siswa dapat termotivasi untuk belajar. Saehana (2013) menyatakan bahwa media pembelajaran yang menggunakan multimedia interaktif dapat meningkatkan pemahaman konsep. Sedangkan (Gilakjani (2012) menyebutkan bahwa ada tiga alasan dan alasan penggunaan multimedia di kelas, diantaraya penggunaannya meningkatkan tingkat minat siswa, meningkatkan pemahaman mereka, dan meningkatkan kemampuan menghafal siswa.

Dengan menggunakan multimedia interaktif, bentuk-bentuk pembelajaran massase yang dikembangkan memiliki kelebihan memperjelas penyajian pesan agar tidak terlalu bersifat verbalistis (dalam bentuk kata-kata tertulis atau lisan belaka), mengatasai keterbatasan ruang, waktu dan daya indera. Penggunaan media secara tepat dan bervariasi dapat mengatasi sikap pasif peserta didik yaitu menimbulkan kegairahan belajar, memungkinkan interaksi yang lebih langsung antara anak didik dengan lingkungan dan kenyataan, memungkinkan anak didik belajar sendiri-sendiri menurut kemampuan dan minatnya, memberikan solusi bila latar belakang lingkungan guru dengan siswa berbeda, dalam hal ini kemampuan media memberikan perangsang yang sama, mempersamakan pengalaman, menimbulkan persepsi yang sama (Sadiman, dkk 1986:17).

\section{KESIMPULAN}

Berdasarkan data yang diperoleh, dari hasil uji coba lapangan dan pembahasan hasil penelitian dapat disimpulkan bahwa: (1) Dengan adanya multimedia interaktif pembelajaran sport massase ini 
mahasiswa dapat mempelajari dan melaksanakan praktik sport massase secara efektif dan efisien dan (2) Dengan adanya multimedia interaktif pembelajaran sport massase ini mahasiswa dapat menguasai materi teori dan praktik sport massase dengan cepat dan benar.

Penulis bersyukur kepada Tuhan YME karena telah dipermudah dalam proses penyusunan, penelitian, penulisan hingga publikasi artikel yang berjudul "Efektifitas Pembelajaran Multimedia Interaktif Sport Massase Untuk Mahasiswa Pendidikan Jasmani, Kesehatan dan Rekreasi FIK-UM. Oleh karena itu penulis mengucapkan terima kasih kepada semua pihak dalam penyusunan artikel ilmiah ini dan juga seluruh komponen yang terlibat dalam penelitian. Penulis berharap artikel ini dapat bermanfaat untuk mahasiswa, atlet maupun pelaku olahraga lainnya dan dapat dijadikan rujukan serta dikembangkan dalam bidang yang relevan dengan keilmuan dan teori yang ada.

\section{DAFTAR PUSTAKA}

Ahmadi, I. K., Amri, S., \& Elisah, T. (2011). Strategi pembelajaran sekolah terpadu. Jakarta: Prestasi Pustaka.

Ampa, A. T. (2015). The Implementation of Interactive Multimedia Learning Materials in Teaching Listening Skills. English Language Teaching, 8(12), 56-62.

Cairncross, S., \& Mannion, M. (2001). Interactive multimedia and learning: Realizing the benefits. Innovations in education and teaching intermational, 38(2), 156-164.

Darmawan, D. (2012). Inovasi pendidikan. Bandung: PT Remaja Rosdakarya, 47-66.

Daryanto. (2015). Media Pembelajaran. Sarana Tutorial Nurani Sejahtera.

Deliyannis, I. (2012). Interactive multimedia. BoD-Books on Demand.

Duffy, G. G. (1993). Rethinking strategy instruction: Four teachers' development and their low achievers' understandings. The Elementary School Journal, 93(3), 231-247.

Dwiyogo, W. D. (2008). Aplikasi Teknologi Pembelajaran Media Pembelajaran Penjas \& Olahraga. Malang: Departemen Pendidikan Nasional Universitas Negeri Malang Fakultas Ilmu Pendidikan.

Efrina, N., \& Dkk. (2013). Pengembangan Multimedia Interaktif Pada Pembelajaran Kimia Untuk Madrasah Aliyah. 2(1), 65-78.

Gilakjani, A. P. (2012). The significant role of multimedia in motivating EFL learners' interest in English language learning. International Journal of Modern Education and Computer Science, 4(4), 57.

Hake, R. R. (1999). Analyzing change/gain scores. Unpublished.[online] URL: http://www. physics. indiana. edu/ sdi/AnalyzingChange-Gain. pdf.

Hamalik, O. (2001). Proses Belajar dan Mengajar. Jakarta: PT Bumi Aksara.

Kemenegpora. (2007). Undang-Undang Republik Indonesia Nomor 3 Tahun 2005; Tentang Sistem Keolahragaan Nasional. Kemenegpora.

Mulyasa. (2012). Manajemen PAUD. PT Remaja Rosdakarya.

Munir, M. (2012). Multimedia konsep \& aplikasi dalam pendidikan. Bandung: Alfabeta.

Nurseto, T. (2011). Membuat media pembelajaran yang menarik. Jumal Ekonomi dan pendidikan, 8(1).

Sadiman, \& Arief, S. (1986). Media Pendidikan: Pengertian, Pengembangan, dan Pemanfaatannya. PT Raja Grafindo Persada.

Saehana, S. (2013). Pengembangan Media Pembelajaran Interaktif Berbasis Komputer Untuk Siswa Smp Kelas Viii. 69-77.

Sugiyono, P. (2015). Metode penelitian kombinasi (mixed methods). Bandung: Alfabeta.

Sulistyorini, \& Basoeki, H. (2012). Sport Massage Seni Pijat Untuk Atlet/Olahragawan Dan Umum. Wineka Media. 
Supriyadi, \& Wardani, H. E. (2009). Anatomi Manusia. Um (Press).

Varol, Y. (2014). The Relationship between attitudes of prospective physical education teachers towards education technologies and computer self-efficacy beliefs. Turkish Online Journal of Educational Technology-TOJET, 13(2), 157-167.

Vernadakis, N., Giannousi, M., Derri, V., Michalopoulos, M., \& Kioumourtzoglou, E. (2011). The impact of blended and traditional instruction in students' performance. Procedia Technology, 1, 439-443.

Wiendartum, Ramalis, T. R., \& Rohmah, H. S. (2007). Pengaruh Pembelajaran Berbasis Multimedia Terhadap Hasil Belajar Fisika. Proceding Of The First International Seminar On Science Education. Jurusan Fisika Fpmipa Upi.

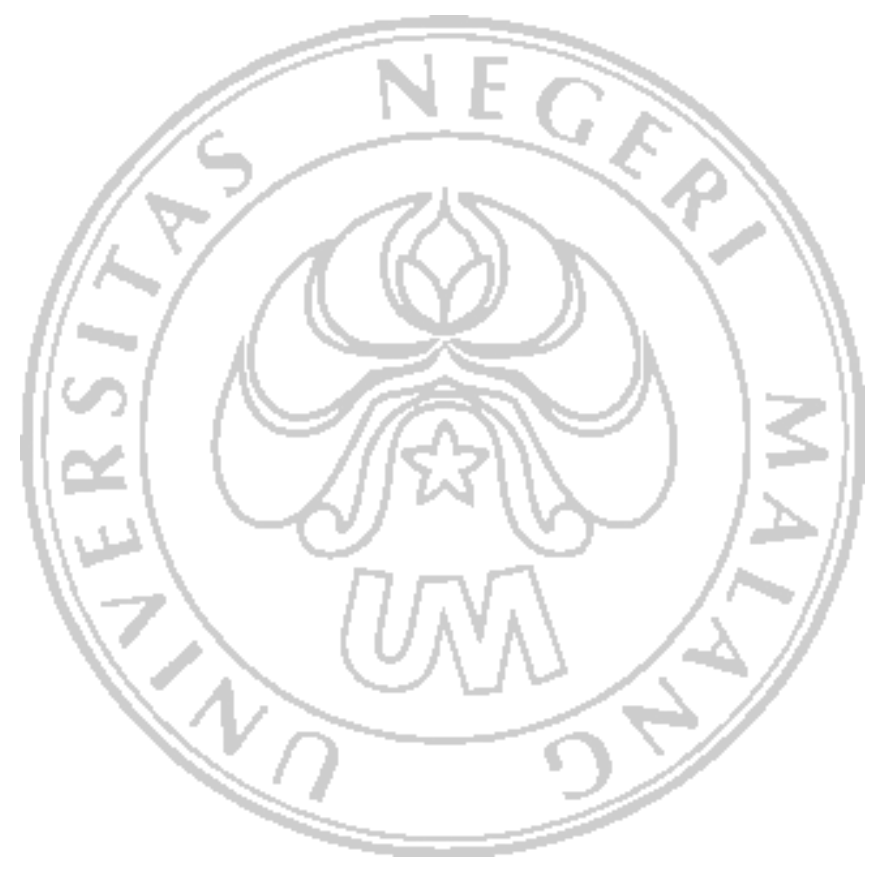

